\title{
EMPRESÁRIOS NA POLÍTICA MUNICIPAL: O PERFIL POLÍTICO DOS CANDIDATOS À PREFEITO NAS ELEIÇÕES 2012 E 2016
}

\author{
Marília Correia Machado ${ }^{1}$
}

\begin{abstract}
Resumo
Este trabalho analisa o perfil dos candidatos autodeclarados empresários à prefeito nas eleições municipais de 2012 e 2016 com a finalidade de aprofundar o conhecimento sobre empresários que adentram na vida política. Para isso, através dos dados do Repositório de dados eleitorais do TSE e do Observatório de Informações Municipais, busca-se avaliar a quantidade de candidatos empresários eleitos e não eleitos; as ideologias partidárias; se estariam presentes em municípios bilionários; patrimônio declarado; o sexo e as regiões geoeconômicas que se candidatam. A metodologia escolhida é a análise exploratória dos dados. As técnicas analíticas são a Análise de Correspondência Múltipla (ACM) e o teste de qui-quadrado. A ACM visa encontrar associações entre as variáveis de pesquisa. Entretanto, para estudar mais afundo estes resultados, utilizou-se o teste qui-quadrado, responsável por comparar as frequências, eviden-ciando a força de associação entre as variáveis. $\mathrm{Na}$ conclusão, foi evidenciado que as variáveis 'eleito' e 'não eleito' não demonstra uma associação com nenhuma das variáveis, impossibilitando uma coleta de padrões. Além disso, foi possível visualizar diferentes padrões de candidatos conforme as regionalidades analisadas. Assim, observou-se que a maioria dos candidatos concorrem nos municípios bilionários, porém os que concorrem, possuem majoritariamente alto patrimônio e ensino educacional superior. Enquanto nos outros municípios, o padrão seria de ensino escolar médio e baixo patrimônio. Inclusive, a variável patrimônio não gerou impacto no gráfico de dimensões da ACM, pois há uma diferença numérica baixa entre o alto e baixo patrimônio. Apesar da maioria dos candidatos serem do sexo masculino, o sexo feminino se destaca pelo número alto de escolaridade superior e médio, do mesmo modo que os homens. O teste de qui-quadrado conseguiu destacar que os candidatos das regiões Centro-Sul e Amazônia possuem alto patrimônio, enquanto na região Nordeste predominava o baixo patrimônio.
\end{abstract}

Palavras-Chave: Empresários; eleições municipais; perfil político; ideologia partidária.

\section{INTRODUÇÃO}

Em geral, quando se fala em empresários, uma abrangência de estudos sobre a definição desse grupo imediatamente vem em mente. Enquanto determinadas obras caracterizam os empresários como aqueles que são proprietários ou gestores do capital (CARDOSO, 1972; TRASPADINI, 2014), outros analisam o empresariado como elite (COSTA, 2015; COSTA;

\footnotetext{
${ }^{1}$ Doutoranda em Ciência Política na UFPR, e-mail: marilia_cmp@hotmail.com
} 
NUNES, 2014; COSTA, 2014). Em outras pesquisas, o empresário é investigado como uma das variáveis consideradas na análise do processo eleitoral (CODATO; CERVI; PERISSINOTTO, 2013; FELISBINO; BERNABEL, KERBAUY, 2012; SCHNEIDER; TESKE, 1992).

Pode-se observar um crescimento no número de estudos sobre empresários na política eleitoral ou que avaliam se a condição de ser empresário implica vantagens nas eleições, seja para o Poder Executivo ou Legislativo (ENGLER, 2018; 2018; CODATO; CERVI; PERISSINOTTO, 2013; FELISBINO; BERNABEL; KERBAUY, 2012; OFFERLÉ, 1999; JONES, 1983; SCHNEIDER; TESKE, 1992; FRANÇA, 2016). Isso ocorre não somente no Brasil, mas também em outras nações que perceberam a presença do empresário no âmbito da política representativa (LI; MENG; ZHANG, 2006; TIRADO, 2015; SCHNEIDER; TESKE, 1992; JONES, 1983).

Assim, apesar de a importância dos estudos sobre os empresários na Ciência Política não ser um fator inédito, neste trabalho, propomos uma abordagem ainda pouco explorada sobre esse tema. Entendendo que o empresário na política abarca uma pluralidade de análises, esta pesquisa centrase no empresário que participa das campanhas eleitorais na política local, especificamente nos municípios brasileiros. Há referências de empresários na política não somente como atores eleitorais, mas também, como aqueles que participam de lobbying (MANCUSO, 2004; LI; MENG; ZHANG, 2006). Por isso, a ênfase desta pesquisa não está nesses indivíduos, e sim nos candidatos e eleitos nas prefeituras brasileiras.

Embora os empresários estejam localizados em vários campos políticos, os estudos concernentes ao empresário autodeclarado como candidato nas prefeituras é um objeto ainda pouco explorado, a despeito de alguns trabalhos analisarem o seu sucesso eleitoral nas capitais brasileiras (FELISBINO; BERNABEL; KERBAUY, 2012; CODATO; CERVI; PERISSINOTTO, 2013; ENGLER, 2018). Por isso, este trabalho justifica-se a partir da realidade de que há poucas pesquisas centradas especificamente na relação de empresários autodeclarados candidatos à prefeitura e seu perfil com a vitória eleitoral (ser eleito) relacionado. Portanto, o objeto desta pesquisa são os candidatos empresários autodeclarados nas eleições municipais brasileiras. Do mesmo modo, o objetivo é analisar o perfil político desses empresários nas prefeituras dos municípios brasileiros nas eleições de 2012 e 2016. Com isso, procura-se entender quem seriam os empresários que se lançam como candidatos, já que, ao estarem se candidatando, tornar-se-ão os selecionados pelos partidos políticos para concorrer na disputa. Assim, como o estudo analisa o perfil de candidatos empresários, deverá considerar, então, as informações sociais, econômicas e políticas dessa ocupação. 
Esta pesquisa é uma análise descritiva, que não visa a um teste de hipótese, ou seja, não há uma ideia anterior (teórica ou derivada de estudos empíricos) buscando verificar determinado fato observado. Logo, salienta-se que a pesquisa almeja estudar quem seriam os candidatos autodeclarados empresários. Para isso, pretende-se encontrar um perfil político de candidatura, conforme as variáveis: i) espectro ideológico-partidário; ii) eleito; iii) patrimônio; iv) grau de escolaridade; v) sexo; vi) ser de município bilionário e vii) regiões geoeconômicas.

A delimitação sobre qual empresariado a pesquisa trataria está relacionada à autodeclaração. É sabido que há formas de pesquisas mais aprofundadas sobre a ocupação que o político usufrui, como a análise biográfica e de trajetória (COSTA, 2010; RODRIGUES, 2002; MARENCO, 1997; 2013). Contudo, em conformidade com o número de empresários autodeclarados concorrentes nas eleições do Poder Executivo municipal nos dois períodos eleitorais, a utilização da autodeclaração nas fichas eleitorais, disponíveis no Tribunal Superior Eleitoral, verificaria a representatividade desse grupo

É percebido que as disputas municipais possuem a capacidade de sinalizar o que está por vir nas urnas nos anos seguintes envolvendo o Poder Executivo (LAVAREDA et al., 2016) e também como, apesar desta importância, são escassos os estudos sobre as eleições municipais (LAVAREDA; TELLES, 2016). Por essa razão, a escolha em estudar estas eleições torna-se mais prudente. Os anos mais recentes, nos quais ocorreram as disputas eleitorais nos municípios brasileiros, foram marcados por acontecimentos diferenciados: enquanto as eleições de 2012 antecederam as Jornadas de Junho de 2013, as eleições de 2016 foram marcadas com a crescente crise político-econômica no país (MANCEBO, 2017). Da mesma maneira, a aprovação da nova legislação sobre financiamento de campanha iniciaria um novo método da forma pela qual o financiamento seria regulamentado na política (BRASIL, 2017). Portanto, a escolha dos dois períodos eleitorias almeja impulsionar futuros trabalhos sobre eleição de prefeitos empresários, partindo das duas disputas recentes e com acontecimentos importantes na política brasileira.

Com isso, tenta-se responder: quem seriam os empresários candidatos à Prefeitura dos municípios brasileiros em 2012 e 2016? Após a definição de qual tipo de empresário deve-se trabalhar, no caso, os autodeclarados, cabe-se, então, classificar as demais características que possibilitam compreender quem seriam esses indivíduos que decidem concorrer nas eleições para prefeito. Por se tratar do empresário que se declarou nas fichas do Tribunal Superior Eleitoral (TSE), a utilização de determinadas variáveis ali contidas possibilita uma abordagem interessante para este trabalho 


\section{REVISÃO LITERÁRIA}

O objetivo deste capítulo é abordar o empresariado na política conforme a literatura da Ciência Política. O argumento desta análise consiste em entender primeiramente o objeto desta pesquisa, direcionando-se depois para o estudo de perfil político desse grupo. Tendo isso em conta, é preciso apresentar teoricamente os estudos de empresários na política, para então discutir o objetivo específico do trabalho.

Não há nesta pesquisa a pretensão de entrar no extenso e complexo debate sobre os conceitos de empresariado, mas sim apresentar a importância do seu estudo, buscando, assim, estudar as relações entre empresário e espaço político, com a finalidade de "trazer indícios que existe uma combinação não excludente dessas atividades" (ENGLER, 2018, p. 323). Esta pesquisa não pretende concluir de modo geral sobre essa relação, mas pode realizar afirmações, a partir de uma análise descritiva, restritas ao espaço temporal a ser estudado.

A Ciência Política vem crescentemente se interessando em estudar os empresários que adentram no âmbito político (SCHNEIDER; TESKE, 1992). A literatura referente a empresariado e política é numerosa (COSTA, 2005), sendo possível dividi-la entre aquelas que apresentam-nos como instrumentos do desenvolvimento econômico (CARDOSO, 1972; SCHMITTER, 1971), como aqueles que estão no pleito eleitoral (CODATO, CERVI, PERISSINOTTO, 2013; FELISBINO; BERNABEL; KERBAUY, 2012) e como aqueles cuja participação estaria presente em outros âmbitos, como o lobbying (MANCUSO, 2004; 2007).

Para explicar o objeto de pesquisa, é necessário descrever brevemente o histórico do empresariado no Brasil, com a finalidade de apontar o momento em que o empresário iniciou sua participação política nesse contexto. Nos anos 1990, a década marcada pelo início do processo democrático brasileiro, os estudos relacionados ao empresariado na política foram retomados na agenda de pesquisa (ENGLER, 2018), debatendo-o como ator político, ou seja, a sua atuação (MANCUSO, 2007); antes desse período, a força do empresariado para influenciar o poder público era considerada fraca (MANCUSO, 2007). 
A Carta Magna de 1988 conseguiu elevar o papel do município no cenário político do Brasil (KERBAUY, 2005). Nesse contexto, considerando que a presença empresarial nos termos organizacionais pode aglomerar-se dentro das esferas políticas (TIRADO, 2015), cabe a análise do que acontece com o empresariado brasileiro. Há trabalhos relacionados aos empresários que almejam cargos eletivos. Em relação aos empresários que participam da política eleitoral, os estudos que relacionam empresários e posições no Poder Legislativo:

(...) são de alguma forma escassos tanto nas pesquisas temáticas que focam no empresariado, (...) quanto nos trabalhos sobre eleições, instituições políticas e Congresso Nacional - que analisam as bases sociais das elites políticas, em geral, não procurando um recorte econômico, ou de uma categoria ocupacional ligada a atividades econômicas (ENGLER, 2018, p. 324).

As análises brasileiras possuem trabalhos que têm se preocupado em identificar as variáveis que afetam as oportunidades daqueles que se lançam nas disputas eleitorais, especialmente para os cargos de deputados federais e senadores (MARENCO, 1997; 2013; RODRIGUES, 2002; 2009; CORADINI, 2001; 2012; ROJAS; CARLOMAGNO, 2014). Esses estudos se questionam sobre o impacto que fatores de diversos tipos têm sobre as possibilidades de um pretendente vir a ser eleito.

Nesse caso, pesquisas sobre a composição do Congresso Nacional revelam que os empresários são enquadrados como o grupo que ocupou mais cadeiras na Câmara de Deputados entre as eleições de 1990 e 2015 (ENGLER, 2018). Nestes termos, Marenco (1997) dedica-se ao estudo de perfil de membros de Legislativo, os deputados, trazendo, como um dos resultados sobre a ocupação empresário, que os indivíduos que alcançaram o primeiro cargo depois dos 40 anos destacam-se por ter uma vida profissional não dependente da carreira pública para sobreviver, podendo abandoná-la quando preferir, diferenciando-se daquele que construiu o nome a partir da reputação de pessoa política. Do mesmo modo, Rodrigues (2009) afirma que o setor empresarial continua sendo o principal "celeiro de abastecimento" do grupo no Poder Legislativo federal, com o total de 230 empresários, tornando-se $37 \%$ do corpo congressista no período analisado.

Contudo, estudar o empresário é, também, especificar a qual empresariado a pesquisa se refere. A questão enunciada decorre do fato de que a classificação dessa ocupação em estudos de perfil ou de composição política é variada. No caso brasileiro, há um contexto social particular, onde pode acontecer uma “personalização dos mandatários, no sentido que são confundidos com os próprios cargos políticos ocupados, com isso, é determinante a proximidade pessoal (...)" 
(ENGLER, 2018, p. 327). Ou seja, a ocupação torna-se uma espécie de característica fundamental do candidato, sendo possível causar uma aproximação pessoal entre ele e os eleitores. Outra dificuldade decorre da existência de casos nos quais os indivíduos possuem atividades econômicas empresariais, mas não se declaram empresários (CORADINI, 2001).

Para esta pesquisa, a autodeclaração será utilizada para o estudo dos empresários na política municipal, pois, apesar de haver tipologias autodeclaradas que podem ser semelhantes à profissão empresarial, a facilidade das fichas frente a um estudo biográfico de todos os prefeitos em território nacional torna o estudo mais viável, e por isso optou-se por essa fonte. Do mesmo modo, para verificar a representatividade de indivíduos na política, há de se considerar o modo pelo qual estes se identificam profissionalmente e qual seria o perfil da ocupação.

Em análises acerca da ocupação de senadores, Marenco (2013), baseado em Rodrigues (2009), define empresário como "englobados em atividades ligadas ao mercado, não importando a dimensão do empreendimento" (RODRIGUES, 2009, p. 22). Por outro lado, considerando os estudos de empresários na política municipal, nas prefeituras, Engler (2018) considera empresário aquele autodeclarado nas fichas de candidatura.

Dito isto, a problemática da pesquisa está centrada nos empresários candidatos nas prefeituras, aqueles autodeclarados que dela participam e também os que conseguem se eleger. Salienta-se que as pesquisas relacionadas a prefeitos empresários são escassas, do mesmo modo como as principais análises sobre esse grupo "focam nos impactos institucionais sobre as estratégias dos atores e os resultados das políticas públicas, objetivando o comportamento, representação de interesses e agenda legislativa, não abordando o perfil destes grupos dirigentes” (ENGLER, 2018, p. $325)$.

As análises sobre o perfil social daqueles que ocupam o poder público consistem em estudar os requisitos para a entrada na política, bem como das características que são excludentes (HOFFMANN-LANGE, 2007; MIRÍADE; PERISSINOTTO, 2009; LORENCETTI, 2016). Por isso, cabe ressaltar que "os estudos de elites pouco se focaram até aqui no nível local ou regional" (ROJAS; CARLOMAGNO, 2014). Podemos, assim, considerar que as análises tanto sobre recrutamento quanto sobre perfil social procuram relações de hierarquia social (GAXIE, 2012).

$\mathrm{O}$ estudo sobre prefeitos e quem seriam aqueles que se candidatam e vencem as eleições estão presentes na pesquisa de Codato, Cervi e Perissinotto (2013). Esses autores buscaram contribuir para o entendimento interno do processo de recrutamento político no Brasil partindo de uma análise do perfil de todos os candidatos a prefeito e, em especial, dos candidatos vitoriosos nas 
eleições municipais de 2012. Os autores destacam que os prefeitos não têm sido muito investigados nessa perspectiva, pois, em geral, estudos sobre eleições municipais estão focados ou em campanhas, ou em partidos, ou em eleitores.

De igual modo, Dufloth et al (2019), ao traçarem os atributos de sucesso eleitoral de prefeitos, refletem sobre o perfil evolutivo dos prefeitos vencedores utilizando-se das variáveis: sexo, idade, escolaridade e ocupação, a fim de encontrar um padrão de perfilagem vitoriosa. Na sua avaliação, apontam que nas eleições de 2008, 2012 e 2016, a principal ocupação declarada era a de “membros superiores do poder público, dirigentes de organização de interesse político e de empresas e gerentes" tendo sua participação praticamente dobrada, passando de $22 \%$ em 2000 para 42\% em 2016 (DUFLOTH et al., 2019, p. 225). Os 'dirigentes de empresas e organizações' foram os que apresentaram crescente participação, evoluindo de 2,3\% em 2000 para 15\% em 2016.

Sendo assim, apesar de os estudos sobre o empresariado na política não serem algo inédito, demonstrou-se que as pesquisas sobre o perfil do empresário ainda são escassas na Ciência Política (LOUREIRO; OLIVIERI, 2002), incluindo as de perfil de candidatos empresários nas prefeituras.

O estudo de variáveis responsáveis pela identificação de oportunidades de candidatos se lançarem nas campanhas eleitorais vem sendo muito estudada no Brasil, especialmente no Poder Legislativo. Já a análise de perfil dos prefeitos não é tão estudada quanto àqueles que ocupam o Congresso Nacional (CODATO; CERVI; PERISSINOTTO, 2013), o que torna a pesquisa em questão ainda mais relevante.

Deste modo, ao utilizar como uma das variáveis sociais o fator 'empresário' para estudar o perfil de prefeitos nas eleições de 2012, Codato, Cervi e Perissinotto (2013) buscaram medir o impacto desta ocupação profissional autodeclarada. Os autores concluíram que, tanto para os urbanos quanto para os rurais, esse era o segundo maior coeficiente de dependência entre as variáveis sociodemográficas, o que significa que ser empresário apresenta resíduo positivo com ser eleito e negativo com não ser eleito. Assim sendo, ser empresário está ligado ao crescimento de chances de ser eleito. Todavia, não ser empresário não significa que o candidato teria necessariamente oportunidades maiores de ser derrotado na disputa municipal. (CODATO; CERVI; PERISSINOTTO, 2013).

Da mesma maneira, em pesquisa visando a estudar o recrutamento de prefeitos nas capitais brasileiras do ano de 2008, Felisbino, Bernabel e Kerbauy (2012) constataram que boa parte dos membros vencedores é "profissional da política e profissional liberal" com, respectivamente, 38,6\% e 26,9\%. Em relação aos que não venceram, estariam centrados em quatro grupos: profissionais da 
política $(28,1 \%)$, profissionais liberais $(22,1 \%)$, profissionais de docência $(14,8 \%)$ e funcionários públicos $(12,1 \%)$. Sobre os empresários, explicaram que alguns grupos profissionais estão subrepresentados nas disputas eleitorais para o Executivo das capitais, a exemplo dos empresários rurais, profissionais manuais e profissionais intelectuais, os quais apresentam uma participação muito pequena, ou seja, apesar de presentes, não estão representados em porcentagem na tabela.

Os autores concluíram que os prefeitos das capitais são peças fundamentais no gerenciamento das principais instituições que conduzem o município. Dessa forma, sabe-se que os estudos sobre elites ressaltam que existem atividades profissionais que podem facilitar a entrada no seleto grupo, e na pesquisa desses autores verifica-se que ser político profissional ou liberal pode ajudar na disputa eleitoral, e, posteriormente, em uma campanha vitoriosa. (FELISBINO; BERNABEL; KERBAUY, 2012).

Por conseguinte, a ocupação 'empresário', em termos de candidatura nos municípios no Brasil em eleições para o Poder Executivo, apresentou uma quantidade exponencial importante em relação às outras ocupações presentes no Tribunal Superior Eleitoral de 2016 (MACHADO; COSTA, 2019). Apesar de estudos anteriores afirmarem que em termos de chances de sucesso eleitoral de empresários e não empresários não serem muito diferentes, houve na última eleição municipal (2016) uma presença relevante de empresários se candidatando (2.246 indivíduos ), tornando-se naquele período eletivo a ocupação com o maior número de candidatos, o que poderá indicar uma possível importância da ocupação frente às demais no momento de lançarem-se nas campanhas.

Engler (2018), por outro lado, analisou empresários de modo diferenciado dos autores citados anteriormente. Ao estudar os prefeitos empresários eleitos em 2016, visando a estudá-los em relação à competência eleitoral e ao sucesso de campanha, o autor utilizou-se da análise de discurso juntamente com prosopografia, auxiliado também, pela análise de características sociais de estudos de perfil, como escolaridade, ocupação, patrimônio e partidos políticos. O autor concluiu que, entre o $\mathrm{N}$ de somente 4 prefeitos empresários eleitos no ano estudado, todos tinham patrimônios declarados milionários, e que metade deles estava em partidos de Centro e tinha ensino superior (completo ou incompleto).

Apesar de essas pesquisas estarem centradas no empresário como ocupação com suposto sucesso eleitoral ou no empresário autodeclarado eleito, esses trabalhos são fundamentais para entender como pesquisadores da Ciência Política abordam empresários e política municipal, fortalecendo o interesse na abordagem sobre o grupo em questão e no aprofundamento de quem 
seriam esses indivíduos. Logo, abordar estudo de perfil político centralizando as características econômicas, políticas, sociais e regionais seria um enfoque que acrescentaria sobre o objeto trabalhado.

\section{METODOLOGIA E RESULTADOS}

São apresentados neste capítulo os métodos de análise, as fontes e as variáveis utilizadas neste trabalho. Primeiramente serão expostas as fontes e variáveis da pesquisa. A exploração destas será por meio de dois métodos: a Análise de Correspondência Múltipla (ACM) - responsável pela incorporação categórica das variáveis buscando o posicionamento ou correlação - e Teste de QuiQuadrado - que verificará a distribuição dos casos, revelando detalhadamente alguma relação entre as variáveis de modo mais específico.

\subsection{METODOLOGIA DE PESQUISA}

Para a determinação de quais variáveis seriam tratadas, compreendendo que as informações estariam contidas nas fichas do Tribunal Superior Eleitoral (TSE), estes dados foram retirados do 'Repositório de dados eleitorais', na janela do website 'Candidatos' retirando, assim, as pastas contidas das eleições de 2012 e 2016. Nessas fichas foram recolhidos os dados e reclassificadas como variáveis aptas para teste: partidos políticos; ocupação; patrimônio e local de candidatura e se o indivíduo foi eleito ou não eleito. A partir do conhecimento sobre o local onde o candidato lançou-se, pôde-se averiguar a região posicionada.

Do mesmo modo, para selecionar o municípios de orçamento bilionário que serão especificados na análise de perfil dos candidatos empresários, o Observatório de Informações Municipais define documentalmente os chamados 'municípios bilionários', na pasta 'Dados Municipais' contida no website e posteriormente, encontra-se organizado em dois documentos separadamente: 'Os municípios bilionários em 2012' e 'Os candidatos a prefeito nos municípios bilionários em 2016 '. 
As fontes utilizadas foram as fichas dos candidatos no Repositório de dados eleitorais do Tribunal Superior Eleitoral (TSE) e do Observatório de Informações Municipais, as quais tratam sobre os dados das eleições brasileiras. A escolha em estudar especificamente as eleições municipais dos anos 2012 e 2016 decorre da possibilidade de localizar, em ambas as datas, todos os candidatos que colocaram em suas fichas a ocupação 'empresário'. Nas eleições anteriores, o candidato que em determinada eleição candidatou-se como empresário poderia repreencher a ficha candidatando-se como político no período eleitoral seguinte.

Dos casos a serem estudados nas duas eleições, obtiveram-se 3.841 unidades coletadas de empresários candidatos. É reconhecida a possibilidade de desvios de informação nas autodeclarações, porém cabe salientar a importância de compreender de que modo uma ocupação está representada após ultrapassar a 'peneira' do recrutamento intrapartidário, bem como a possibilidade de a ocupação possuir um padrão entre os candidatos e eleitos. Também é interessante destacar que, ainda que possa haver distorção pontual relacionada a casos individualizados, o fato de o trabalho possuir cerca de 3.600 casos sob análise indica um número de observações que podem minimizar distorções, dada a finalidade do trabalho que seria de identificar padrões.

\subsubsection{Variáveis da pesquisa}

- $\quad$ Eleito: Pretende-se organizar os empresários nas categorias 'eleito' e 'não eleito’ com a finalidade de compreender se há padrões de perfil entre essas duas escalas a partir da associação entre elas e as demais variáveis da pesquisa.

- $\quad$ Orçamento municipal: Agrupados como aqueles municípios que apresentaram uma receita orçamentária superior à média da receita orçamentária nacional nos anos de 2012 e 2016, totalizando 92 municípios bilionários para esta pesquisa.

- Grau de escolaridade: Pretende-se verificar se existe alguma relação de proximidade entre esta categoria e os candidatos empresários. Para isso, foi feita uma análise descritiva estatística relevante para indicar o perfil dos membros deste grupo da elite local: 'ensino superior'; 'ensino médio'; 'ensino fundamental' e 'lê e escreve'.

- Partido no espectro ideológico: Partido político cujo candidato lançou-se nas eleições, baseando-se na literatura de Berlatto, Codato e Bolognesi (2016), que separou os partidos em: i) grande esquerda; ii) pequena esquerda; iii) grande centro; iv) pequeno centro; v) grande direita; vi) pequena direita; vii) fisiológicos. Porém, para esse trabalho, foi englobado entre 
partidos de Direita, Centro e Esquerda. A partir disso, para este trabalho, o tratamento dos dados foi feito com a ferramenta $\mathrm{R}$, que auxiliou identificar e medir visando a conseguir resultados alinhados com os objetivos.

- Patrimônio: Serão separados em ‘baixo patrimônio’ e ‘alto patrimônio’ e incluídos os candidatos empresários que colocaram nas fichas do TSE o patrimônio autodeclarado. Para a utilização desta dicotomia, foi calculada a média de todos, a qual, sendo superior. foi considerada como 'alto' e abaixo dela, como ‘baixo'.

- Sexo: Separado entre 'masculino’ e ‘feminino' com a finalidade de entender o modo como está distribuído os gêneros entre as candidaturas empresariais e como estão associados com as outras variáveis.

- Região geoeconômica: Utilizou-se da classificação de Corrêa (1989): 'Amazônia', 'Nordeste' e 'Centro-Sul', para definir onde os candidatos se localizam e sua distribuição em conformidade com as outras variáveis para, assim, complementar o perfil dos empresários analisados.

\subsection{RESULTADOS DA ACM}

Para investigar quais atributos estão associados com os candidatos empresários, o método escolhido foi o de Análise de Correspondência Múltipla (ACM). Este modelo permite "explorar as associações entre a totalidade de variáveis estudadas para construir um espaço no qual se constituem diferentes perfis de candidatos" (RESENDE; CANTU, 2009, p. 3).

O primeiro contato de cientistas sociais com análises geométricas de dados acontece por causa das obras de Pierre Bourdieu, que "incluem quadros que representam espaços sociais em planos cartesianos demarcados por um par de eixos" (KLÜGER, 2018, p. 68). Esses espaços foram construídos a partir de aplicações da técnica chamada análise de correspondências múltiplas (ACM), variante da análise geométrica de dados que usa os dados categóricos, ou seja, qualitativos, para conseguir diferenciar os agentes e posicioná-los conforme o plano (KLÜGER, 2018).

A Análise de Correspondência Múltipla (ACM) tem a finalidade de tratar as variáveis de pesquisa. Em suma, a ACM faz parte de um conjunto amplo de técnicas chamadas 'Análise Geométrica de Dados' que visa descrever e analisar as relações entre uma grande quantidade de variáveis e suas categorias (BERTONCELO, 2016). Conforme Bertoncelo (2016), a diferença entre 
esse método e demais para as Ciências Sociais é que as "relações entre as variáveis e suas modalidades podem ser visualizadas por meio das distâncias relativas que as separam nas chamadas "nuvem de modalidades" (BERTONCELO, 2016 p. 1).

A etapa trata do Gráfico de dispersão das categorias das variáveis com centroide:

GRÁFICO 1 - GRÁFICO DE DISPERSÃO NAS ELEIÇÕES 2012 e 2016

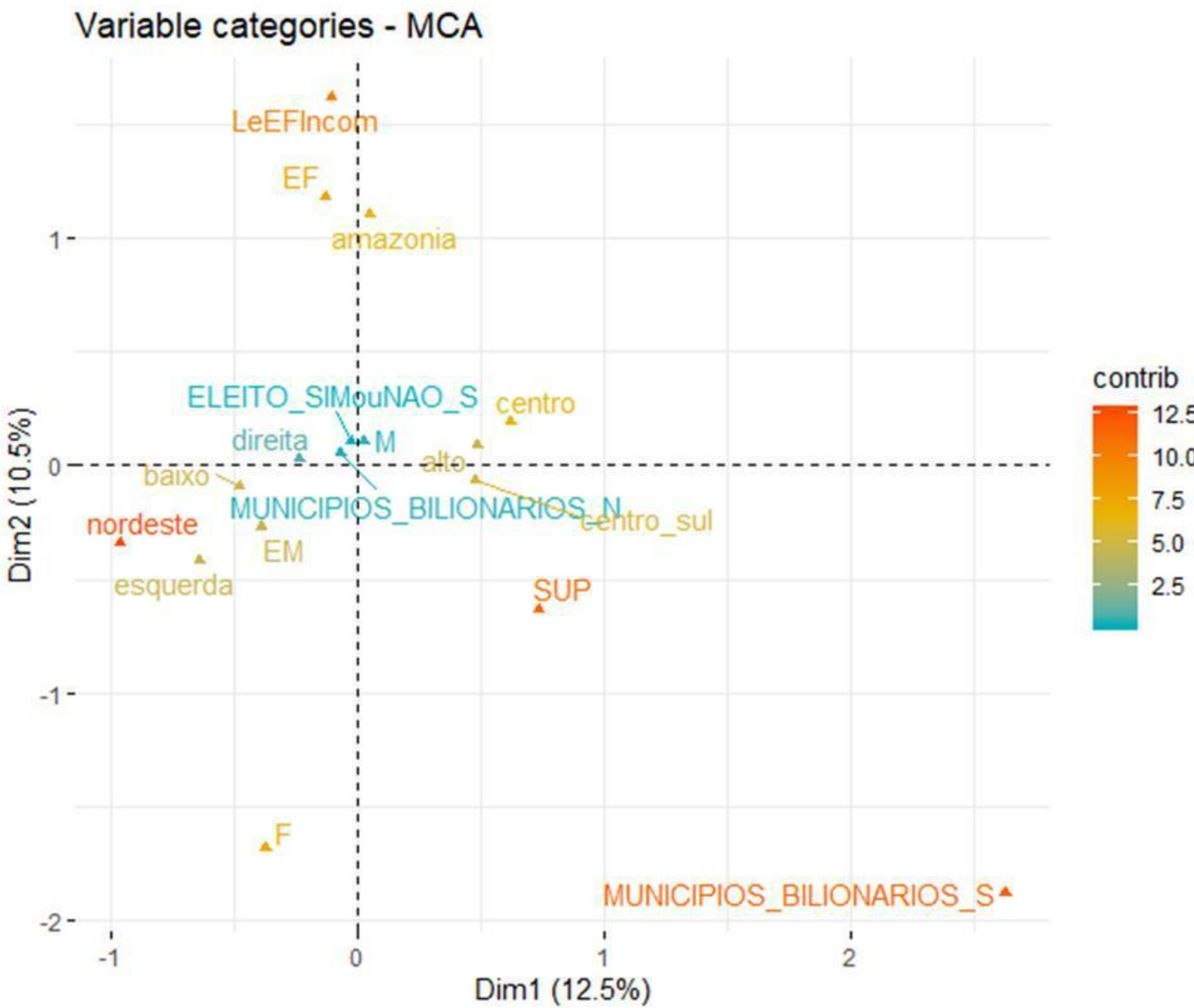

Fonte: TSE 2012 e 2016; Observatório de Informações Municipais.

Elaboração: a autora.

O Gráfico 1 comporta somente $23 \%$ da variância explicada no modelo. Ainda assim, explicita para observação que a variável região possui interessante tendência de correlação com as variáveis: ideologia partidária e escolaridade. Empresários candidatos do Nordeste tiveram 
candidaturas majoritárias à esquerda e escolaridade ensino médio. Candidatos empresários da Amazônia possuem outro perfil político: com a escolaridade que lê e escreve e grau de instrução até ensino fundamental (completo e incompleto). Já os candidatos do Centro-Sul têm ensino superior e partidos de ideologia de Centro. Além disso, é interessante observar a variável patrimônio, pois ela se correlaciona à variável região também, porém especificamente nas regiões Nordeste (baixo patrimônio) e Centro-Sul (alto patrimônio). A propósito, o patrimônio não gera impacto na Dimensão 1.

As variáveis 'município bilionário' e 'sexo feminino' estão distantes. Mas isso os torna relevantes, pois se leva a compreender que há resíduo, indicando variâncias não analisadas neste trabalho, mas que poderiam ser explicadas caso fossem inseridas no modelo outras variáveis explicativas.

Assim, cabe pontuar que a utilização dos dois anos eleitorais juntos decorre do fato de que se fossem feitos separadamente iria prejudicar a variância, já que o Gráfico 1 comprova que há a incapacidade de estabelecer um padrão entre eleitos e não eleitos. A não separação ocorreu porque o trabalho não ia ter como pormenorizar, o trabalho iria perder precisão. Por fim, como a ACM possui baixa variância, explicando pouco as associações entre as variáveis, o teste qui-quadrado possui a função de explicar as correlações.

\subsection{RESULTADOS DO TESTE QUI-QUADRADO.}

Já a contribuição do teste de qui-quadrado para o trabalho decorre da necessidade da interpretação das correlações de modo mais específico do que a ACM. Sendo assim, para entender melhor a relação entre as variáveis categóricas associadas, parte-se para o uso do $\mathrm{x}^{2}$.

A relevância do qui-quadrado dá-se por ser "um dos testes estatísticos mais antigos e um dos mais usados em pesquisa social" (PIVETA, 2003, p. 28). O teste de $\mathrm{x}^{2}$ consiste no método de análise que compara "os resultados observados com os resultados esperados para verificar se há ou não diferença significativa entre as distribuições" (CERVI, 2014, p. 20), sendo utilizado em variáveis categóricas e depende graus de liberdade (GL) como parâmetro externo para o cálculo.

Segundo Barbetta (1999), é uma medida entre as frequências a serem observadas. Piveta (2003) completa ser um método que possibilita testar a significância da associação de duas variáveis qualitativas.

Para esse trabalho, utilizaremos duas tabelas que deram resultados. 
TABELA 1 - ASSOCIAÇÃO ENTRE ESCOLARIDADE E SEXO

\begin{tabular}{cccccc}
\multirow{2}{*}{ Sexo } & \multicolumn{5}{c}{ Escolaridade vs. Sexo } \\
& $\begin{array}{c}\text { Ensino } \\
\text { fundamental }\end{array}$ & $\begin{array}{c}\text { Ensino } \\
\text { médio }\end{array}$ & Lê e escreve & $\begin{array}{c}\text { Ensino } \\
\text { superior }\end{array}$ & Total \\
& 18 & 107 & 4 & 90 & 219 \\
& 4.591 & 0.073 & 13.409 & 10.122 & 0.059 \\
& 0.082 & 0.489 & 0.018 & 0.411 & \\
Masculino & 0.036 & 0.061 & 0.012 & 0.083 & \\
& 0.005 & 0.029 & 0.001 & 0.024 & \\
& 481 & 1646 & 343 & 994 & 3464 \\
& 0.290 & 0.005 & 0.848 & 0.640 & 0.941 \\
Total & 0.139 & 0.475 & 0.099 & 0.287 & \\
& 0.964 & 0.939 & 0.988 & 0.917 & \\
& 0.131 & 0.447 & 0.093 & 0.270 & \\
& 499 & 1753 & 347 & 1084 & 3683
\end{tabular}

Qui-Quadrado: 29. 978; p -valor: 1.395e-06; GL:3.

Fonte: TSE 2012 e 2016.

Na Tabela 1, observa-se que a variável sexo feminino tem alto nível associativo com o ensino médio e ensino superior. Proporcionalmente, há uma quantidade maior de homens no ensino médio e no superior, porém se destaca que, entre as 219 candidatas, 90 delas obtiveram grau de instrução no ensino superior e 107 obtiveram o grau até o ensino médio. É curioso notar que, apesar de a maioria dos candidatos empresários nos municípios brasileiros serem os homens, as mulheres que se candidatam possuem, majoritariamente, o ensino superior e médio.

TABELA 2 - CORRELAÇÃO ENTRE PATRIMÔNIO E ESCOLARIDADE 


$\begin{array}{lccccc} & \begin{array}{c}\text { Ensino } \\ \text { fundamental }\end{array} & \begin{array}{c}\text { Ensino } \\ \text { médio }\end{array} & \text { Lê e escreve } & \begin{array}{c}\text { Ensino } \\ \text { superior }\end{array} & \text { Total } \\ \text { Alto } & 231 & 837 & 181 & 589 & 1838 \\ & 1.305 & 1.636 & 0.354 & 4.264 & 0.499 \\ & 0.126 & 0.455 & 0.098 & 0.320 & \\ & 0.463 & 0.477 & 0.522 & 0.543 & \\ \text { Baixo } & 0.063 & 0.227 & 0.049 & 0.160 & \\ & 268 & 916 & 166 & 495 & 1845 \\ & 1.300 & 1.630 & 0.353 & 4.248 & 0.501 \\ & 0.145 & 0.496 & 0.090 & 0.268 & \\ \text { Total } & 0.537 & 0.523 & 0.478 & 0.457 & \\ & 0.073 & 0.249 & 0.045 & 0.134 & \\ & 499 & 1753 & 347 & 1084 & 3683 \\ & 0.135 & 0.476 & 0.094 & 0.28=94 & \end{array}$

Qui-quadrado: 15.09; p-valor: 0.001741; GL:3.

Fonte: TSE 2012 e 2016.

Neste caso, os que possuem patrimônio alto associam-se com ter ensino médio, da mesma maneira como ter ensino médio está associado com baixo patrimônio. Entretanto, o qui-quadrado comprovou também que os candidatos empresários que possuem nível superior possuem alto patrimônio. A única exceção para essa ordem são os que estão localizados no grau de ensino fundamental que está associado ao baixo patrimônio.

\section{CONSIDERAÇÕES FINAIS}

Neste trabalho, pôde-se concluir que o indivíduo autodeclarado empresário, ao menos aquele que assumiu o empresariado como ocupação nas fichas, possui diferentes perfis a partir da análise das variáveis utilizadas na pesquisa. Cabe ressaltar que esta dissertação está direcionada ao estudo de perfil político de períodos eleitorais específicos, logo, não se pode concluir em definitivo sobre os candidatos empresários que concorreram nos municípios desde a redemocratização.

Em síntese, com a totalidade analisada nesta pesquisa, a Análise de Correspondência Múltipla tornou possível comprovar que a variável 'eleito' não resultou em associação com as outras variáveis de pesquisa, impossibilitando determinar um perfil entre os empresários candidatos e os vencedores durante as eleições de 2012 e 2016. Esta primeira observação já torna interessante a conclusão de que, em termos de padrões, os candidatos empresários não obtiveram uma definitiva nos períodos mais recentes das eleições municipais Executivas. 
A análise estatística descritiva demonstrou que apesar de a maioria dos candidatos estar localizada em partidos políticos de Direita, há uma presença grande de candidatos nos partidos políticos de Esquerda, o que tornaria prudente outro trabalho mais específico em relação aos perfis de empresários à esquerda, se haveria uma ideologia específica desse grupo nesses partidos.

Embora a Análise de Correspondência Múltipla comporte somente 23\% da variância, a associação entre região, ideologia partidária e escolaridade tornou prudente uma averiguação mais abrangente das correlações. A partir disso, o teste de qui-quadrado conseguiu viabilizar a análise de 11 associações, das quais duas foram consideradas ausentes de associação.

Neste quesito, o teste de qui-quadrado trouxe evidências mais específicas sobre o perfil político dos empresários. Ao utilizar a variável município bilionário, que visa a compreender se há um interesse do candidato em tentar se eleger nesses municípios, comprova-se que apesar de outros municípios terem mais indivíduos concorrentes, os candidatos que escolhem lançar campanha nesses municípios de alta renda média possuem ensino escolar superior e alto patrimônio. Diferentemente dos outros municípios, que atraíram empresários com ensino escolar médio e baixo patrimônio.

Na mesma linha, a diferença regional dos candidatos também é evidente. A ACM permitiu entender que nas três regiões estudadas, Centro-sul, Amazônia e Nordeste, havia diferentes perfis de empresários que concorriam. O que torna prudente observar a importância de trazer à luz os estudos de perfil dos prefeitos empresários. Compreendendo a diferença orçamentária e cultural do Brasil, os candidatos empresários que tentam as eleições, de fato, mudam em conformidade com o local.

Os resultados que demonstram a questão do não encontro de padrão entre eleito e não eleito, os motivos para essa falta de padrão não são o objetivo deste trabalho. Porém, esse achado recomendaria um aprofundamento sobre as possíveis associações entre eles nas outras eleições. É possível especular com este trabalho que, como somente duas eleições foram analisadas, tornou-se improvável apontar perfis, especialmente nos momentos eleitorais nos quais eventos políticos e econômicos ocorreram. Assim, para comprovar a falta de padrão entre os eleitos empresários, seria necessário um estudo eleitoral dos municípios mais amplo.

Conclui-se, por fim, que para logar um padrão mais determinante sobre os empresários prefeitos será necessário ampliar, provavelmente, os períodos eleitorais e trazer outras variáveis de pesquisa não citadas neste trabalho, já que foi possível perceber nas análises da ACM o espaço 
entre variáveis, o que indica que há peculiaridades não estudadas até aqui, mas que merecem ser compreendidas como aprofundamento da temática.

\section{REFERÊNCIAS}

ABDI, Hervé; VALENTIN, Dominique. Multiple Correspondence Analysis, In: SALKIND, Neil (ed.). Encyclopedia of Measurement and Statistics, 2007.

ALMEIDA, de Frederico. As elites da Justiça: instituições, profissões e poder na política da justiça brasileira, Revista de Sociologia e Política, v.22, n.52, dez/2014.

BARBETTA, Pedro A. Estatística Aplicada às Ciências Sociais. Florianópolis: Editora da UFSC, 1999. 3.ed.

BERLATTO,F.; CODATO, A.; BOLOGNESI, B. Da polícia à política: explicando o perfil dos candidatos das forças repressivas de Estado à Câmara dos Deputados, Revista Brasileira de Ciência Política, n. 21, set/dez 2016.

BERTONCELO, Edison. O uso da Análise de Correspondências Múltiplas nas Ciências Sociais: possibilidades de aplicação e exemplos empíricos, 40 Encontro Anual da ANPOCS, 2016.

BOURDIEU, Pierre. O poder simbólico. Trad: Fernando Tomaz, Difel difusão editorial Ltda: Lisboa, 1989.

BORDIGNON, R.R. Recrutamento e Modalidades de Entrada na Carreira Política: candidatos aos cargos legislativos no Rio Grande do Sul (1998-2006), Política \& Sociedade, v. 16, n. 35, 2017.

BRAGA, M. S. S; VEIGA, L. F.; MIRÍADE, A. Recrutamento e perfil dos candidatos e dos eleitos à Câmara dos Deputados nas eleições de 2006. Revista Brasileira de Ciências Sociais, v. 24, n. 70, p. $124-142,2009$. 
BRAGA, M; CASSOTTA, L. P.; SABBAG, G. 2017. Partidos e Representação na PolíticaLocal: perfil e vínculos politico-partidários dos vereadores paulistas. Bogotá, Revista Colômbia Internacional, v.91, pp.117-150

BRASIL, 2017. Decreto Lei No 13.487 de 06 de outubro de 2017. Diário Oficial da República Federativa do Brasil, Brasília, DF, 9 out. 2017. Disponível em: <http://www.planalto.gov.br/ccivil_03/_ato2015-2018/2017/lei/113487.htm> Acesso em: 29.02.2020

BRASIL. Tribunal Superior Eleitoral. Repositório de dados eleitorais. Brasília, 2020. Disponível em: <http://www.tse.jus.br/eleicoes/estatisticas/repositorio-de-dados-eleitorais-1/repositorio-dedados-eleitorais> Acesso em: 09.03.2020

BRASIL. Observatório de Informações Municipais. Os municípios bilionários em 2012. Salvador, 2012. Disponível em: <http://www.oim.tmunicipal.org.br/abre_documento.cfm?arquivo=_repositorio/_oim/_documentos/ 0A02E0F3-B67C-9A08-8879B86D15C8168923072012111749.pdf\&i=1967> Acesso em: 09.03.2020.

BRASIL. Observatório de Informações Municipais. Os candidatos a prefeito nos municípios bilionários em 2016, Rio de Janeiro, 2016. Disponível em: <http://www.oim.tmunicipal.org.br/abre_documento.cfm?arquivo=_repositorio/_oim/_documentos/ F8023EBD-C979-2A6E-F64FB29C48B8598827082016093622.pdf\&i=3045> Acesso em: 09.03.2020.

CARDOSO, Fernando Henrique. Empresário industrial e desenvolvimento econômico no Brasil. São Paulo: Difusão Europeia do Livro, 1972. - Política e desenvolvimento em sociedades dependentes :ideologias do empresariado industrial argentino e brasileiro. Rio de Janeiro: Zahar, 1971. 
CERVI, Emerson U. Análise de dados categóricos em Ciência Política: Uso de testes estatísticos em tabelas de contigência com fontes secundárias de dados, Independente, Curitiba: Pós-graduação em Comunicação e Pós-graduação em Ciência Política - UFPR, 98 p. 2014.

CODATO, A; COSTA, L.D; MASSIMO, L. Classificando ocupações prévias à entrada na política: uma discussão metodológica e um teste empírico, Opinião Pública, v. 20, n. 3, dez/ 2014.

CODATO, A; CERVI, E; PERISSINOTTO, R.M. Quem se elege prefeito no Brasil? Condicionantes do sucesso eleitoral em 2012, Cadernos ADENAUER, v. 14, n. 2, jun/2013.

CORADINI, O.L. Categorias sócio-profissionais, titulação escolar e disputas eleitorais, Revista de Sociologia e Política, v. 20, n. 41, fev/2012.

. Em nome de quem? Recursos sociais e Recrutamento de Elites políticas. Rio de Janeiro:

Relume Dumará, 2001.

COSTA, P.R.N. Como os empresários pensam a política e a democracia: Brasil, anos 1990. Opinião Pública, v.11, n.2, out/2005.

$\neg$ ᄀา Elite empresarial e elite econômica: o estudo dos empresários. Revista Sociologia e Política, v.22, n. 52, dez/2014.

COSTA, P.R.N. Os empresários enquanto elite: a pesquisa empírica. In: Perissinotto, Renato e Codato, Adriano Nervo. (Org.). Como estudar elites. 1ªed.Curitiba: Editora Ufpr, 2015, v. 1, p. 217 246

COSTA, P.R.N; COSTA, L. D.; NUNES, W. . Os senadores-empresários: recrutamento, carreira e partidos políticos dos empresários no Senado brasileiro (1986-2010). Revista Brasileira de Ciência Política (Impresso), p. 227-253, 2014. 
COSTA, Luiz Domingos. Os representantes dos estados no Congresso: composição social e carreira política dos Senadores brasileiros. Campinas - SP: Universidade Estadual de Campinas - Unicamp, 2010.

COSTA, L. D.; CODATO, A. Profissionalização ou popularização da classe política brasileira? Um perfil dos senadores da República, In: MARENCO, A. Org. Os eleitos: representação e carreiras políticas em democracias [online], Porto Alegre: Editora UFRGS, 2013. Link: http://books.scielo.org/id/bfwrk/pdf/marenco-9788538603849-06.pdf Acessado em: 24.01. 2020.

CORRÊA, R.L. A organização regional do espaço brasileiro, Geosul, n.8, 1989.

DUFlOTH, S.C; HORTA, C.J.G; SILVA, da M.M; COSTA, da M.L.M; ROCHA, de M.S. Atributos e chances de sucesso eleitoral de prefeitos no Brasil, Revista de Administração Pública, v.53, n. 1, jan/fev 2019.

ENGLER, I.G.F. Os "gestores" na política: Um estudo sobre a mobilização da competência empresarial e o sucesso nas eleições para prefeito de 2016, Workshop Empresa, empresário e sociedade, jun/2018.

. Empresários ou políticos? Recursos socioeconômicos e posicionamentos profissionais de deputados federais no Brasil, Mediações - Revista de Ciências Sociais, v.23, n.3, jul/2018.

FEIJÓ, C.A; VALENTE, E; CARVALHO, de P.G.M. Além do PIB: uma visão crítica sobre avanços metodológicos na mensuração de desenvolvimento sócio econômico e o debate no Brasil contemporâneo, Estatística e Sociedade, n.2, nov/2012.

FELISBINO, Riberti de Almeida; BERNABEL, Rodolpho Talaysis; KERBAUY, Maria Teresa Miceli. Somente um deve vencer: as bases de recrutamento dos candidatos à prefeitura das capitais brasileiras em 2008, Revista de Sociologia e Política, v. 21, n. 41, fev/2012. 
FRANÇA, L.B. Perfil e estilo de liderança dos prefeitos-empresários no Brasil pós-eleição de 2016, 2016.

GAXIE, Daniel. As lógicas do recrutamento político, Trad: Patrícia C. Reuillard, Revista Brasileira de Ciência Política, n. 8, maio/ago 2012.

. Les logiques du recrutement politique. Revue Française de Science Politique, Paris, v. 30, n. 1, p. 5-45, fév/1980.

GEHLBACH, Scott; SONIN, Konstantin. Businessman Candidates: Special-Interest Politics in Weakly Institutionalized Enviroments, William Davidson Institute Paper Number 733, dez/2004.

HOFFMANN-LANGE, U. Methods of Elite Research. In: DALTON, R. J.; KLINGEMANN, H.-D. (Eds.). The Oxford Handbook of Political Behavior. Oxford, England: Oxford University Press, p. 910-926. KARPIK,2007.

JONES, L.J. Public Pursuit of Private Profit? Liberal Businessmen and Municipal Politics in Birmingham, 1865-1900, Business History, v.25, n. 3, 1983.

KERBAUY, M.T.M. As câmaras municipais brasileiras: perfil de carreira e percepção sobre o processo decisório local, Opinião Pública, n.2, v.11, out/2005.

KLÜGER, Elisa. Análise de correspondências múltiplas: fundamentos, elaboração e interpretação, BIB, n.86, out/2018.

LAVAREDA, Antonio; TELLES, Helcimara. A lógica das eleições municipais, Rio de Janeiro: FGV Editora, 2016.

LAVAREDA, Antonio; TELLES, Helcimara. Como o eleitor escolhe seu prefeito: campanha e voto nas eleições municipais. Editora FGV, 2015. 
LAVAREDA, Antonio et al. Eleições municipais de 2012 e sinais para adiante. In: LAVAREDA A.; TELLES, H. A lógica das eleições municipais, Rio de Janeiro: FGV Editora, 2016.

LI, H; MENG, L; ZHANG, J. Why Do Entrepreneurs Enter Politics? Evidence from China, Economic Inquiry forthcoming, v. 44, 2006.

LORENCETTI, M.A. Estudo de uma profissão (da) política: os advogados na Câmara dos deputados (1945-2010), Universidade Federal do Paraná (dissertação de mestrado), Curitiba, 2016.

LOUREIRO, Maria Rita; OLIVIERI, Cecilia. Lés elites économiques face au développement et à la démocratie: les patrons e les hauts fonctionnaires du gouvernement au Brésil. Cahiers du Brésil Contemporain, Paris, n.47/48, p. 267- 289, 2002.

MANCEBO, D. Crise político-econômica no Brasil: Breve análise da educação superior, Revista Educação e Sociedade, v.38, n.141, out/dez 2017.

MACHADO, M.C; COSTA, P.R.N. O político empresário: onde se localizam os candidatos e eleitos nos municípios brasileiros de 2016, VI Fórum Brasileiro de Pós-graduação em Ciência Política, Belém, jul/2019.

MACHADO, M.C. Empresários na política: Uma breve análise do perfil individual e paternal dos prefeitos das capitais brasileiras (2012-2016), X Seminário Nacional de Sociologia e Política, 2019.

MANCUSO, W.P. O Lobby da indústria no Congresso Nacional: Empresariado e política no Brasil contemporâneo, Dados: Revista de Ciências Sociais, Rio de Janeiro, v. 47, n.3, 2004.

. O empresariado como ator político no Brasil: Balanço da literatura e a agenda de pesquisa, Revista de Sociologia e Política, v.28, jun/2007.

MARENCO DOS SANTOS, A. Nas fronteiras do campo político: raposas e outsiders no Congresso Nacional. Revista Brasileira de Ciências Sociais, p. 87-101, 1997. 
. (org). O que podemos explicar estudando carreiras políticas? In: Os eleitos: representação e carreiras políticas em democracias [online]. Porto Alegre: Editora da UFRGS, 2013, pp. 31-51. ISBN 978-85-386-0384-9. Available from doi: 10.7476/9788538603849. Also available in ePUB from: http://books.scielo.org/id/bfwrk/epub/marenco-9788538603849.epub. Acesso em: 03.03.2020

MARTINS, T.C; KERBAUY, M.T.M. O perfil da elite política local: Uma análise da autopercepção dos vereadores sobre a representação, Revista Eletrônica de Ciência Política, v.8, n.2, 2017.

MIRÍADE, A; PERISSINOTTO, R.M. Caminhos para o parlamento: Candidatos e eleitos nas eleições para deputado federal em 2006, Dados- Revista de Ciências Sociais, v. 52, n. 2, 2009.

NAITO, S.D.N.P. Análise de correspondências generalizada. Dissertação de mestrado em Bioestatística - Universidade de Lisboa, Lisboa, 2007, 156p.

OFFERLÉ, M. La profession politique 19 e-20e siècles, Paris, Berlin, p. 93-134, 1999.

PEREIRA, Júlio C. R. Análise de Dados Qualitativos. São Paulo: EDUSP-FAPESP, 1999

PIVETA, Jaqueline. Módulo para ensino-aprendizagem em Análise de Correspondência Múltipla Integrado ao SESTAT.NET. Dissertação de mestrado, Universidade Federal de Santa Catarina, março/2003.

PRADO, M.V.B. Métodos de análise de correspondência múltipla: estudo de caso aplicado à avaliação da qualidade do café, Dissertação de mestrado, Universidade Federal de Lavras, 2012.

PRATTI, L.P; PESSINE, K.M; CAMPOS, M.M. Perfil socioeconômico dos legisladores subnacionais: O que a reeleição trouxe de mudanças nas últimas legislaturas da Assembleia Legislativa do Estado do Espírito Santo, Agenda Política, v.4, n.3, set/dez 2016. 
PRATTI, Luana Puppin. Perfil Social, recrutamento e trajetórias políticas: uma análise dos representantes do Legislativo Estadual capixaba, 1986-2010. Dissertação em Sociologia. Vitória: Universidade Federal do Espírito Santo, 2013.

REIS, E.A; REIS, I.A. Análise descritiva de Dados, Relatório Técnico do Departamento de Estatística da UFMG, jun/2002.

RESENDE, R.C; CANTU, R. Performance eleitoral e perfis: análise da Assembléia Legislativa do Paraná (1998-2006), 33º Encontro Anual da Anpocs, Caxambú, out/2009.

RODRIGUES, L.M. Mudanças na classe política brasileira, [s.I], Publifolha, 2009.

.Partidos, ideologia e composição social: um estudo das bancadas partidárias na câmara dos deputados. São Paulo: Edusp, 2002.

ROJAS, F.A.G; CARLOMAGNO, M.C. Elite política local e legislativo municipal no estado de São Paulo: partidos, ideologia e composição social, Agenda Política, v.2, n.1, 2014.

SCHMITTER, Philippe C. Interest Conflict and Political Change in Brazil.Stanford: Stanford University Press, 1971.

SCHNEIDER, M.; TESKE, P. Toward a theory of the political entrepreneur: Evidence from local government, American Political Science Review, v.86, n.3, set/1992.

SILVA, E.L; AGUIAR, D.C. Análise descritiva e de correspondência múltipla aplicada aos países perseguidores do cristianismo (portas abertas) no ano de 2012, Encontro Nacional de Educação, Ciência e Tecnologia, UEPB, 2012.

SPECK, B.W; MANCUSO, W.P. O que faz a diferença? Gastos de campanha, capital político, sexo e contexto municipal nas eleições para prefeito em 2012, Cadernos Adenauer, v.14, n.2, 2013. 
TIRADO, Ricardo. Enfoques teóricos y conceptos sobre el poder político empresarial, Revista

Mexicana de Ciências Políticas y Sociales, n. 225, set/ dez 2015.

TRASPADINI, Roberta. A teoria da (inter) dependência de Fernando Henrique Cardoso, $2^{\mathrm{a}}$ ed, São Paulo: Outras Expressões, 2014, 192p.

VEIGA, L.F; ROSS, S.D. Os determinantes da avaliação da economia na eleição presidencial brasileira em 2014, Opinião Pública, v.22, n.3, dez/2016.

WEBER, M. The profession and vocation of politics. In: LASSMAN, P.; SPEIRS, R. (Eds.). Weber: political writings. Cambridge: Cambridge University Press, 1994. p. 309-369. 